\title{
A evasão na educação superior: o estado da arte das pesquisas no Brasil a partir de 1990
}

\author{
José da Silva Santos Junior \\ Giselle Cristina Martins Real
}

Resumo: O objetivo é produzir um levantamento de pesquisas sobre evasão na educação superior, realizadas a partir da década de 1990 no País, constituindo o "Estado da Arte" sobre essa temática. Respondendo às críticas sobre esse tipo de pesquisa, o presente trabalho vai além do mapeamento bibliográfico produzido com a leitura e análise de resumos, uma vez que, a partir da leitura integral de textos selecionados, identifica os enfoques aí abordados, situados temporalmente no contexto de expansão do acesso a este nível de ensino. Metodologicamente, recorreu-se aos bancos de dados Scielo, GT11/Anped, Capes e BDTD, localizando-se 07 teses, 34 dissertações e 31 artigos. Constata-se que os estudos relacionados a causas e a estratégias de controle da evasão são os mais numerosos, representando mais da metade dos trabalhos analisados. Observou-se que, ainda, há divergências conceituais e metodológicas, não pontuadas na literatura analisada. Portanto, considera-se que a evasão na educação superior vem se apresentando como importante temática de pesquisa, em que o estabelecimento de um campo de discussão sólido poderá contribuir para melhor compreensão do processo.

Palavras-chave: Políticas educacionais. Acesso à educação superior. Evasão estudantil.

\section{Dropout from higher education: the state of the art of researches in Brazil since 1990}

Abstract: The goal is to survey what dropout is like from higher education since the 1990s in the country, constituting the "State of the Art" on this topic. Responding to criticism of this kind of research, this study goes beyond bibliographic mapping produced based on the reading and analysis of summaries since there was a thorough reading of selected texts. Hence, it identifies the highlights given to these works, temporarily located in the context of expanding access to this level of education. Methodologically, the following databases were used: Scielo, GT11/Anped, Capes and BDTD, from which 07 theses, 34 dissertations and 31 articles were located. It was proved that the studies relating to causes and strategies for dropout control are the most numerous ones, accounting for over half of the analyzed studies. It was observed that there are conceptual and methodological differences, which were not mentioned in the analyzed literature. Therefore, it is considered that dropout from higher education has been presenting itself as an important theme for research, in which the establishment of a solid field of discussion can contribute to better a understanding of the process.

Key words: Educational policies. Access to higher education. Student dropout. 


\section{Introdução}

As políticas educacionais tornaram-se importante foco de pesquisas nos últimos anos, com ampla diversidade de temas tratados pelos trabalhos publicados e/ou apresentados nos espaços acadêmicos do campo educacional (SOUZA, A., 2014), os quais dão enfoque tanto para as políticas de educação básica quanto de educação superior.

Quando se trata da educação superior, tal diversidade é justificada pelo contexto de expansão do nível de ensino em questão a partir da década de 1990 no Brasil. Neste caso, os estudos relacionados ao acesso e à permanência na educação superior vêm sendo alvo de um número cada vez mais elevado de produções acadêmico-científicas, visto que as duas últimas décadas configuraram-se como um período fértil para a consolidação de tais estudos, uma vez que novas possiblidades de pesquisa foram vislumbradas, a partir de incrementos relevantes na formulação e na implementação de políticas para acesso à educação superior. Processo que tem recebido influências tanto pelo crescimento da demanda interna (OLIVEIRA, 2007), como pelo contexto e diretrizes supranacionais marcados pelo processo de globalização (TORRES, 2001; ROBERTSON, 2009; BALL, 2001; OLIVEIRA, 2009).

Neste trabalho, procura-se, a partir de contextualização do processo de expansão do acesso, dar enfoque aos estudos sobre evasão de estudantes em cursos de graduação nas Instituições de Educação Superior (IES), uma vez que esta temática adquire relevância no processo de consolidação do sistema de educação superior brasileiro.

Nessa direção, o objetivo pretendido para o presente trabalho foi produzir um levantamento de estudos e pesquisas sobre evasão na educação superior, realizados a partir da década de 1990 no País.

Com características bibliográficas, o estudo baseia-se na modalidade de pesquisa conhecida na literatura como "Estado da Arte" ou "Estado do Conhecimento", que tem o desafio de "[...] mapear e de discutir uma certa produção acadêmica em diferentes campos do conhecimento, tentando responder que aspectos e dimensões vêm sendo destacados e privilegiados em diferentes épocas e lugares" (FERREIRA, 2002, p. 258).

Romanowski e Ens (2006) destacam a importância dos trabalhos denominados "Estado da arte", considerando-os essenciais para a constituição do campo teórico de determinada área de estudo.

Particularmente, o presente trabalho vai além do mapeamento bibliográfico evidenciado a partir da análise e leitura de resumos, o que responde às críticas apontadas por Ferreira (2002), uma vez que parte de leitura integral de textos selecionados, o que possibilita identificar, de fato, os enfoques ali contidos, situados temporalmente no contexto de expansão do acesso à educação superior.

Destaca-se, ainda, que são incipientes os “estados da arte” sobre essa temática. O Instituto Nacional de Estudos e Pesquisas Educacionais “Anísio Teixeira” (Inep) apoiou financeiramente a produção de 11 Estados da Arte sobre educação, sendo que das temáticas tratadas, apenas uma versava sobre a educação superior, ainda de forma bastante genérica e estando limitada ao período de 1968 a 1995 (FÁVERO; OLIVEIRA, 2012). Ainda, destaca-se o estudo de Morosini et al. (2011) que analisou o período de 2000 a 2011, identificando um corpus documental de 7 trabalhos publicados em periódicos qualificados junto ao sistema Qualis da Coordenação de Aperfeiçoamento de Pessoal de Nível Superior (Capes). No levantamento 
produzido na presente pesquisa foi possível identificar somente um estudo dessa natureza, que discute a evasão no contexto da avaliação institucional (BAGGI; LOPES, 2011), abarcando o Banco de Teses da Capes, no período de 2008 a 2009.

Metodologicamente, recorreu-se aos bancos de dados: Scientific Eletronic Library Online (SciElo), Grupo de Trabalho 11 da Associação Nacional de Pós-Graduação e Pesquisa em Educação (GT11/Anped) ${ }^{1}$, Banco de Teses da Capes e Biblioteca Digital Brasileira de Teses e Dissertações (BDTD) do Instituto Brasileiro de Ciência e Tecnologia (IBICT), a fim de selecionar os trabalhos relacionados ao objeto aqui pesquisado, realizados no País no contexto de expansão do acesso à educação superior, visualizado a partir da década de 1990.

A seleção dos trabalhos foi realizada entre os meses de abril/2014 e janeiro/2015, utilizando-se como termos de busca "evasão" e "evasão acadêmica". e selecionados 72 trabalhos ${ }^{3}$, os quais serão analisados na segunda seção.

A leitura dos trabalhos foi realizada com o intuito de se identificar o principal foco de pesquisa abordado, o que levou à seleção das vertentes que fundamentará a análise por meio de categorização das subtemáticas abordadas.

Adota-se a metodologia de categorização com o intuito de captar os itens de pesquisa relacionados ao objeto em investigação em seus aspectos gerais, uma vez que Minayo (2000 apud SILVA; VELOSO, 2013, p. 728) argumenta que as categorias analíticas "[...] retêm historicamente as relações sociais fundamentais e podem ser consideradas balizas para o conhecimento do objeto nos seus aspectos gerais. Elas mesmas comportam vários graus de abstração, generalização e de aproximação".

O problema norteador para o trabalho é explicitado com a seguinte questão: quantos são os trabalhos científicos e quais os enfoques abordados aos estudos que tratam da evasão de estudantes em cursos de graduação, no Brasil, a partir da década de 1990?

Buscando resposta para esta questão, dividiu-se o trabalho em duas seções. Na primeira delas, discute-se o processo de expansão do acesso à educação superior a partir da década de 1990, com a apresentação de dados nacionais que revelam a realidade brasileira. Entendese que tal discussão é fundamental para a compreensão e análise dos trabalhos relacionados à evasão acadêmica, uma vez que os temas estão interligados. A segunda seção é dedicada à análise dos trabalhos que tratam especificamente da evasão de estudantes em cursos de graduação no País, sendo este o principal ponto em que se pretende aprofundar a discussão.

\section{As políticas de expansão e o acesso à educação superior a partir da década de 1990}

Em um contexto histórico, o ingresso à educação superior no Brasil esteve restrito a uma pequena parcela da população, o que caracterizou a vigência de um "sistema de elite" até meados dos anos 2000, período a partir do qual se vislumbraram elevações substantivas no número de estudantes que conseguiram ingressar no sistema, elevando-se para um patamar

\footnotetext{
${ }^{1}$ A opção por considerar no universo da pesquisa as Reuniões da Anped, em detrimento de outros eventos, leva em conta os critérios de periodicidade e antiguidade do evento e da presença de GT específico sobre as políticas de educação superior.

${ }^{2}$ Na página do GT11 da Anped, a busca inicial foi realizada com a leitura dos títulos dos trabalhos apresentados em cada edição da reunião.

${ }^{3}$ Destes, 07 são teses de doutorado, 34 são dissertações de mestrado e 31 são artigos.
} 
referenciado como "sistema de massa" a partir de 2003, conforme consideram Gomes e Moraes $(2012)^{4}$ ao analisar a taxa de crescimento de matrícula bruta no País.

Mesmo após este período de transição, o processo de expansão do acesso continuou em curso, conforme pode ser visto no gráfico 1, em que se apresenta uma série histórica com os números de alunos matriculados nos cursos de graduação a partir de 1980:

\section{Gráfico 1- Evolução da matrícula na educação superior de graduação por categoria ad- ministrativa/Brasil 1980-2012}

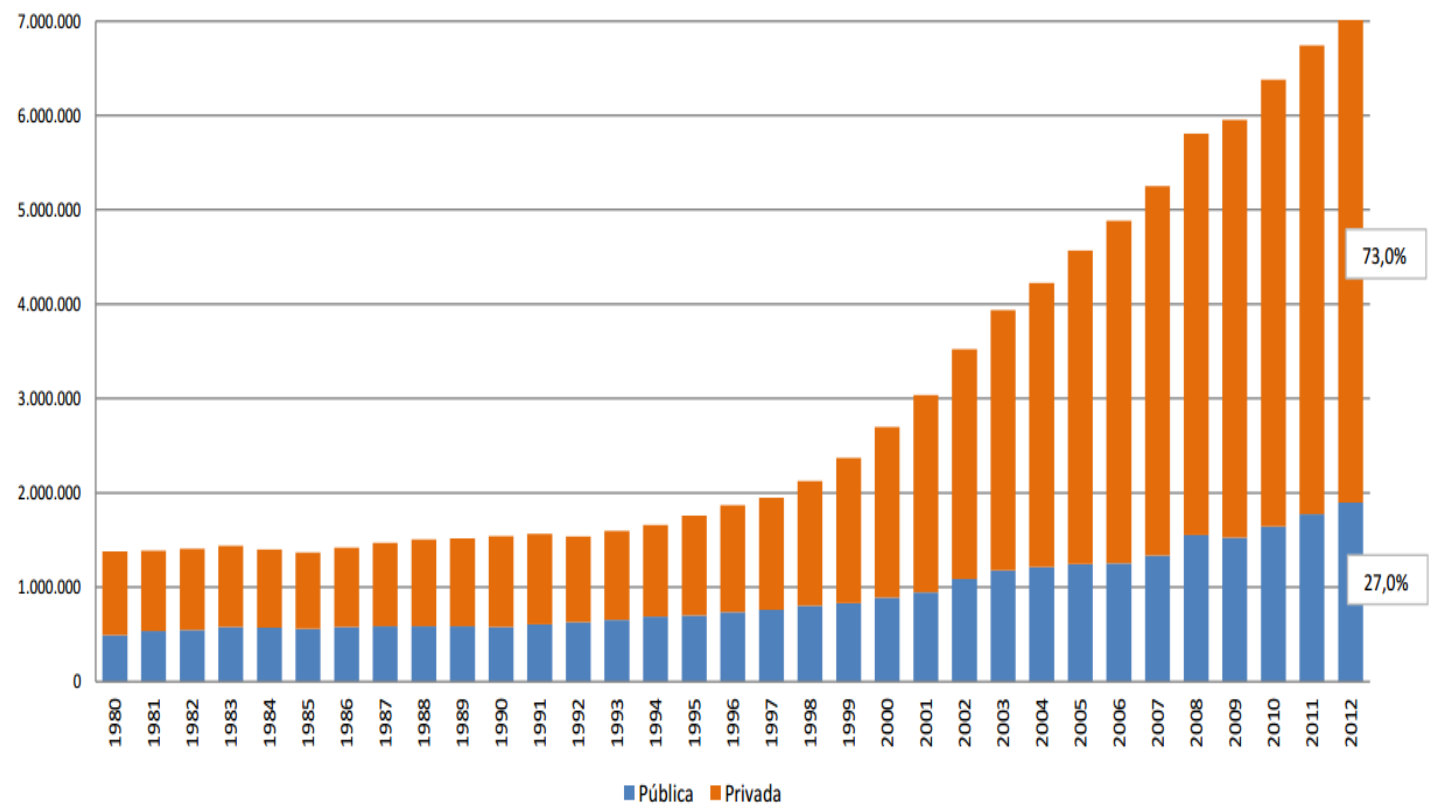

Fonte: BRASIL. MINISTÉRIO DA EDUCAÇÃO. Censo da Educação Superior 2012. Brasília, DF, 2013.

Disponível em: < http://www.andifes.org.br/wp-content/files_flutter/1379600228mercadante.pdf>. Acesso em: 10 abr. 2015.

A partir de 1998 a expansão se torna mais visível, refletindo as iniciativas públicas adotadas na educação superior nas duas últimas décadas, o que se deu, inicialmente, pelo predomínio de políticas focalizadas no setor privado, e, posteriormente, com a formulação de políticas para o setor público, seguido de aumentos expressivos do número de IES com fins lucrativos (DOURADO, 2002; SGUISSARDI, 2008; OLIVEIRA, 2009).

Dentre os programas e ações criadas neste movimento de expansão do acesso, destacaram-se: o Fundo de Financiamento Estudantil (Fies) em 1999, e o Programa "Universidade para Todos" (Prouni) em 2005, ambos criados para estimular o acesso à educação superior na rede privada; o Programa "Universidade: Expandir até ficar do tamanho do Brasil" em 2006 e o "Programa de Apoio a Planos de Reestruturação e Expansão das Universidades Federais" (Reuni) em 2007, direcionados à expansão das universidades federais, com a criação de novas

\footnotetext{
${ }^{4}$ Adotando Trow como referência, Gomes e Moraes apontam o "sistema de elite" como aquele que atende até $16 \%$ da população entre 18 e 24 anos e "sistema de massa" quando atende entre $16 \%$ e $50 \%$ desta parcela. Aquele sistema que atende um percentual maior que $50 \%$ ao grupo citado, é considerado, assim, como "sistema de acesso universal".
} 
Instituições Federais de Ensino Superior (Ifes), novos campi e consolidação das instituições já existentes.

Com a influência deste conjunto de programas, o percentual de alunos matriculados nos cursos de graduação presenciais elevou-se de modo expressivo, observando-se um crescimento de aproximadamente $248,17 \%$ entre os anos de 1991 a 2010, conforme pode ser inferido a partir do gráfico 1 .

Outro fator de crescimento que contribuiu muito para fertilizar os números da expansão universitária é a criação do Sistema Universidade Aberta do Brasil (UAB) em 2006, que ampliou de modo significativo o acesso à educação superior, por meio da Educação à Distância (EaD). De acordo com dados divulgados pelo Censo da Educação Superior, em 2012, a $\mathrm{EaD}$ foi responsável por $15,8 \%$ de todas as matrículas efetuadas na educação superior, o que reforça a sua relevância no processo de ampliação do acesso.

Nesse contexto de expansão, o Exame Nacional do Ensino Médio (Enem), criado em 1998, também adquiriu relevância para o movimento de acesso em discussão, tendo modificado o modo de ingresso em instituições públicas e privadas do País por meio do Sistema de Seleção Unificada (SiSU), de 2009, o qual substituiu o vestibular em algumas IES, sobretudo nas federais.

Convém destacar que, com o "sistema de massa" construído na educação superior brasileira, embora o ingresso aos cursos de graduação continue com características meritocráticas, fez-se necessário a adoção de políticas compensatórias, para possibilitar a igualdade de oportunidades de ingresso a todas as camadas da sociedade (TROW, 2005). Nesse sentido, visualizou-se nos últimos anos a entrada de estudantes nas universidades com perfis socioeconômicos diferenciados (RISTOFF, 2013).

Diante disso, entrou em vigor em 2012 a Lei N. 12.711, para regulamentar, dentre outras providências, o sistema de ingresso à educação superior pública federal por meio de cotas sociais e raciais, configurando-se como medida relevante ao adquirir importância estratégica para o processo de consolidação do sistema de massa na educação superior brasileira, com a inclusão de uma parcela da população tradicionalmente fora desta etapa (MARQUES, 2013).

Por conseguinte, diante de diversos alvos de investigação, a literatura vem se tornando farta ao discutir as questões relacionadas ao acesso de modo conjunto à permanência estudantil (SILVA; VELOSO, 2013; FELICETTI; MOROSINI, 2009; ZAGO, 2006; ALMEIDA et al., 2012). A discussão que vem se alargando procura indicar que a permanência de modo efetivo no curso iniciado também é fator que compõe o conceito de acesso à educação superior, que passa a envolver o ingresso, a permanência e a formação do acadêmico.

Com o intuito de abarcar a demanda por permanência estudantil, algumas ações específicas foram firmadas no setor público, com destaque para o Programa Nacional de Assistência Estudantil (Pnaes) ${ }^{5}$, formulado em 2008, para atendimento aos estudantes do segmento federal, e o Programa Nacional de Assistência Estudantil para as Instituições de Educação Superior Públicas Estaduais (Pnaest), criado em 2010. Tais programas foram criados com finalidades bastante próximas, almejando, de modo genérico, ampliar as condições de acesso e permanência à educação superior, minimizar os efeitos das desigualdades sociais e regio-

\footnotetext{
${ }^{5}$ Tal programa foi elevado à política governamental por meio do Decreto $\mathrm{n}^{\mathrm{o}}$. 7.234, de 19 de julho de 2010.
} 
nais, bem como promover inclusão social pela educação superior, e reduzir as taxas de retenção e de evasão.

Pode-se observar que é a partir do crescimento do número de ingressantes à educação superior, deflagrado, particularmente, a partir de 1990, em que a educação brasileira atende aos percentuais de uma educação de massa, que a evasão passa a configurar como pauta da agenda pública brasileira.

Em estudo divulgado em agosto de 2013 no XXVI Encontro nacional de pró-reitores de graduação das universidades federais ${ }^{6}$, apresentou-se o panorama preliminar da evasão no ensino superior das Ifes brasileiras ${ }^{7}$, em que a média da evasão tendeu a estabilizar em $13 \%$ a partir de 2010.

Entretanto, Silva Filho et al. (2007) realizaram estudo em período anterior, compreendendo os anos de 2000 a 2005, em que utilizaram o conjunto de IES brasileiras. Como resultado, constataram que os índices de evasão mediaram em torno de $22 \%$, sendo que as instituições públicas apresentaram média de $12 \%$ e as privadas, de $26 \%$. Para os referidos autores, os números obtidos representam um problema que afeta o resultado dos sistemas educacionais, uma vez que o número de estudantes que iniciam e não concluem um curso representam desperdícios sociais, acadêmicos e econômicos.

Nesse sentido, esses números podem refletir, de certo modo, as contradições presentes na educação superior brasileira. E, inseridos neste cenário de expansão e contradições, os pesquisadores vislumbraram novas possibilidades para suas análises, o que culminou em números crescentes de estudos relacionados ao acesso e à permanência na educação superior no Brasil, a partir da década de 1990. Mais precisamente, as publicações relacionadas à evasão, embora ainda incipientes, elevaram-se substancialmente e, sobretudo, a partir de 2011, o que justifica a necessidade de se conhecer os rumos tomados pelos pesquisadores quando aceitam por objeto esta temática.

\section{A evasão na educação superior como objeto nas pesquisas educacionais}

Com o panorama de expansão da educação superior em curso, os estudos relacionados à evasão ganharam corpo em compasso ao aumento do número de estudantes matriculados nos cursos de graduação das IES brasileiras, embora ainda considerados escassos na literatura (SILVA, 2013; SILVA FILHO et al., 2007).

Em outros países, esta temática já vem sendo debatida há algumas décadas. Desde meados de 1960, modelos teóricos vêm sendo desenvolvidos com o intuito de se entender melhor o fenômeno da evasão, conforme destaca Freitas (2009).

No contexto sul-americano, verifica-se a presença de estudos recentes, visando, sobretudo, à identificação de índices de evasão e à adoção de estratégias de controle. Tendo como base o ano de 2000, Parrino (2009) reuniu os dados referentes ao ingresso à educação dos jovens entre 18 e 29 anos e as taxas de evasão em cinco países sul-americanos, quais sejam, Argentina, Chile, Brasil, Uruguai e Paraguai, constatando que o Brasil possui o menor índice de evasão (14\%) no ano considerado na pesquisa.

\footnotetext{
${ }^{6}$ Neste sentido, ver: Nunes (2013).

${ }^{7}$ Destaca-se que neste estudo foram utilizadas oito instituições como amostra.
} 
No Brasil, as preocupações com este fenômeno iniciaram-se de modo efetivo em 1995, entrando para a agenda governamental a partir do "Seminário sobre evasão nas universidades brasileiras”, organizado pela Sesu/MEC, em fevereiro de 1995 (KIPNIS, 2000). No seminário foi instituída a "Comissão Especial de Estudos sobre a Evasão nas Universidades Públicas Brasileiras", configurando-se como um dos primeiros esforços para identificar as causas do fenômeno da evasão no País e sugerir medidas para minimizar os índices observados nas instituições de educação superior públicas, partindo de uma uniformização do processo de coleta e tratamento de dados.

Nesse sentido, corrobora para esta constatação o fato de que os trabalhos localizados nos bancos de dados utilizados na pesquisa datam majoritariamente de períodos posteriores a $1995^{8}$, com exceção do artigo de Bueno (1993), fruto de exposição feita em mesa redonda intitulada "A evasão nos cursos de graduação da USP".

A partir da identificação de pontos de discussão comuns entre os trabalhos seleciona$\operatorname{dos}^{9}$, procedeu-se com a categorização de temáticas-chave ${ }^{10}$, identificadas como vertentes de pesquisa, com o intuito de fundamentar a análise em pauta.

Essa metodologia se enquadra na abordagem qualitativa da pesquisa social, especialmente levando em conta que se trata de pesquisa do tipo bibliográfica e, portanto, parte-se da leitura compreensiva do conjunto do material coletado, por meio de articulação entre o objetivo do estudo, a base teórica e os dados empíricos (MINAYO, 2012).

Os resultados obtidos são apresentados na tabela abaixo:

Tabela 1- Vertentes de estudo com a temática evasão na educação superior após 1990

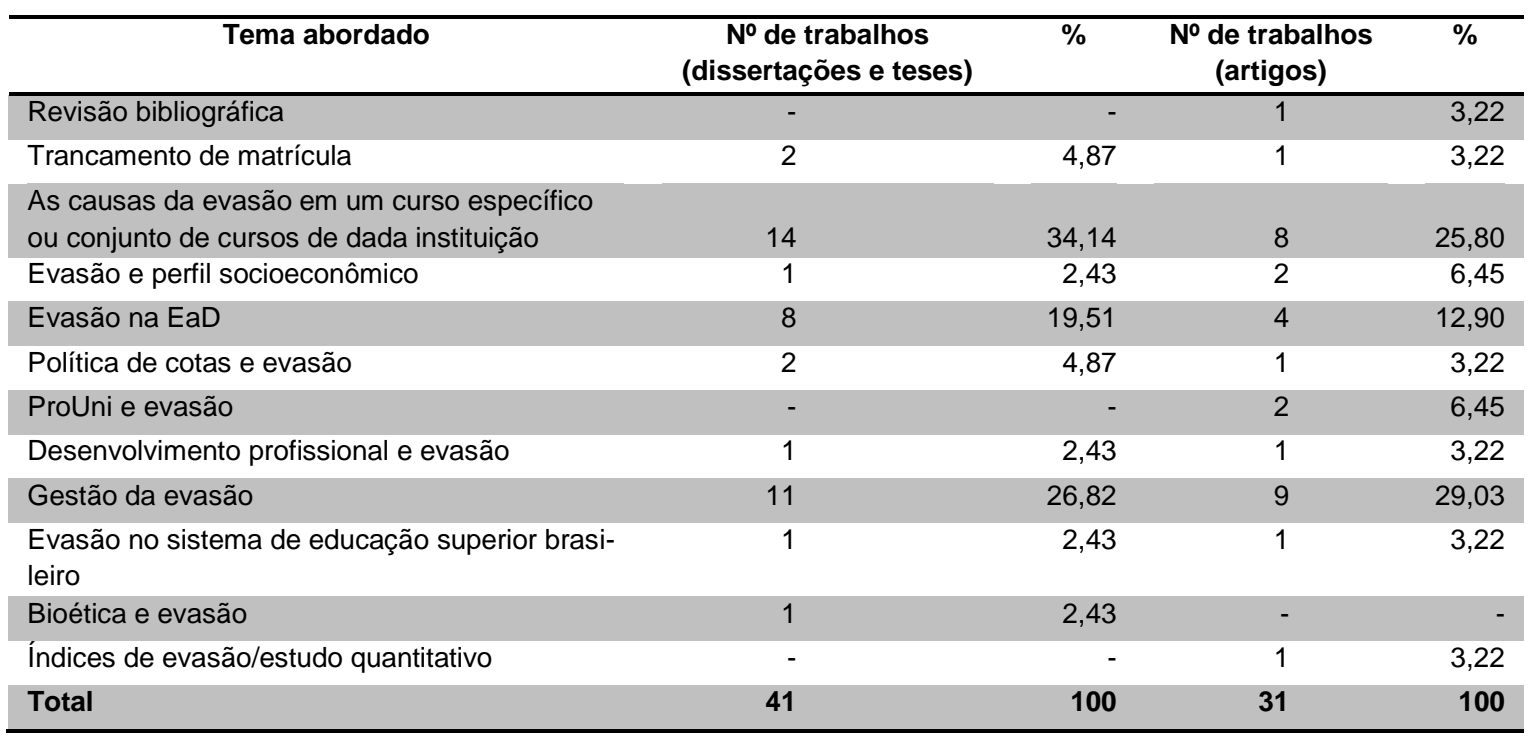

Fonte: Elaboração própria a partir do levantamento de trabalhos realizado

\footnotetext{
${ }^{8}$ Ressalta-se que não foi utilizado filtro temporal na pesquisa realizada nos banco de dados.

${ }^{9}$ Alguns trabalhos relevantes que tratam de evasão na educação superior e não encontrados nos bancos de dados pesquisados, foram utilizados durante a discussão, mas não foram incluídos nos percentuais apontados na tabela 1 .

${ }^{10}$ Verificou-se que alguns trabalhos tratavam de mais de uma temática categorizada. Nesses casos, elegeu-se o principal tema abordado para a inclusão na tabela.
} 
A partir do levantamento realizado, constata-se que há uma complexidade intrínseca em relação ao fenômeno da evasão, uma vez que, embora se perceba certa variedade de tratamentos dados ao processo, ainda há muito que se discutir, considerando a dinâmica de crescimento da educação superior no Brasil e os meandros que a envolvem, os quais têm possibilitado ampliações nas vertentes de pesquisa.

Para Baggi e Lopes (2011), que realizaram revisão de literatura com o tema, esta complexidade envolve questões pedagógicas, psicológicas, sociais, políticas, econômicas, administrativas, dentre outras. Entretanto, tal complexidade pode ser observada desde questões conceituais, em que se verifica um emaranhado de definições para o fenômeno da evasão, à multiplicidade de metodologias para identificação de seus índices (PEREIRA JUNIOR, 2012).

Em relação ao conceito, para Baggi e Lopes (2011), trata-se da "saída do aluno da instituição antes da conclusão do seu curso (p. 370)". Abbad, Carvalho e Zerbini (2006, p. 02) definem evasão como a "desistência definitiva do aluno em qualquer etapa do curso". No entanto, a Comissão instituída pela Sesu em 1995 distinguia três tipos para o processo, quais sejam: evasão de curso, quando o estudante desliga-se do curso superior em situações diversas tais como abandono, desistência, transferência ou reopção, exclusão por norma institucional; evasão da instituição, quando o estudante desliga-se da instituição na qual está matriculado; e evasão do sistema de ensino superior, quando o estudante abandona de forma definitiva ou temporária o ensino superior (BRASIL, 1997). Neste caso, como exemplificação, o trancamento de matrícula tem sido referenciado como uma modalidade de evasão temporária.

Outras questões conceituais também são apresentadas na literatura, como é o caso da relação entre evasão e exclusão, em que Bueno (1993, p. 13) considera que tais processos não devem ser confundidos. Para o autor "A palavra evasão pode estar significando uma postura ativa do aluno que decide desligar-se por sua própria responsabilidade”. Já a exclusão “implica na admissão de uma responsabilidade da escola e de tudo que a cerca por não ter mecanismos de aproveitamento e direcionamento do adolescente que se apresenta para uma formação profissionalizante". Para Bueno, o processo pode ser visto de outra maneira, assumindo-se a existência de duas dimensões relacionadas ao abandono: uma delas relativa às perspectivas do aluno e a outra ao processo de exclusão, inegavelmente presente no âmbito institucional.

Em relação às questões metodológicas, Silva (2012) afirma que há uma multiplicidade de cálculos para avaliar o processo de evasão, sendo que há discrepância entre tais modelos, uma vez que alguns analisam a movimentação de alunos em apenas um ano, não captando o processo de retenção. Por outro lado, outros cálculos abordam períodos de quatro ou cinco anos do curso, o que culmina no englobamento dos fenômenos de evasão e de retenção no mesmo cálculo, em que também ocorre o agravante da vaga do estudante evadido, ocupada por outros processos, como de Portadores de Diplomas e Transferências, mascarar o fenômeno da evasão.

Nesta direção, foram encontrados trabalhos que identificaram os índices de evasão a partir de equações distintas (VELOSO, 2001; SILVA FILHO et al., 2007) e outros que realizaram acompanhamento de trajetória escolar (MASSI, 2013; SOUZA, J., 2014), sendo que estes últimos estudos apresentam-se mais propícios para a obtenção de números fidedignos do 
fenômeno, uma vez que identificam os evadidos caso a caso, permitindo maiores possibilidades de intervenções.

Tratando de outras vertentes, algumas questões têm sido debatidas com mais afinco pelos pesquisadores, conforme pode ser visualizado na tabela 1, sendo as causas da evasão em um curso, conjunto de cursos ou instituição específicos o principal foco de estudo, representando $34,14 \%$ das teses e dissertações e $25,80 \%$ dos artigos selecionados. Cumpre-se observar que Morosini et al. (2011) já indicava, em seu levantamento, essa característica nas produções entre 2000 e 2011. Nesta categoria, os pesquisadores vêm apontando os motivos que levam ao fenômeno da evasão, sendo amplamente utilizado no diagnóstico a entrevista ou a aplicação de questionário aos evadidos.

Por outro lado, Tinto (1975) propôs o entendimento do processo de evasão a partir de percurso longitudinal, em que os principais fatores relacionados a este fenômeno seriam aqueles que envolvem a integração entre o indivíduo e os sistemas acadêmico e social. Para o autor, os estudantes menos envolvidos com a instituição possuem maiores chances de abandonar o curso iniciado, tendo em vista que comumente não se integram com demais alunos de mesma turma e/ou da instituição como um todo.

Partindo das concepções de Tinto, Pereira Junior (2012) buscou identificar a relação entre o processo de evasão aos compromissos do estudante relacionados à sua graduação, ao curso e à instituição, concluindo que há necessidade de maior preocupação e acompanhamento dos estudantes ingressantes pelas instituições com aspectos relacionados ao curso e à carreira profissional.

Nesta direção, o trabalho de Pereira Junior (2012) faz parte de um percentual expressivo de trabalhos encontrados, realizados tanto em instituições públicas quanto privadas, com o intuito de discutir a evasão com um viés mais direcionado ao fator institucional, em que a maioria deles apresenta medidas de combate à evasão. Tais trabalhos foram incluídos na categoria "gestão da evasão", correspondendo a 26,82\% das dissertações e teses e $29,03 \%$ dos artigos localizados.

Nestes estudos citados são abarcadas discussões diversas, tais como: identificação dos fatores anteriores ao ingresso que contribuem para a evasão (BRISSAC, 2009); opiniões e estratégias de coordenadores em relação ao fenômeno (LIMA, 2012); e mecanismos de controle da evasão (NEY, 2010; TONTINI; WALTER, 2014).

Estas discussões assumem relevância no atual contexto, visto que a ampliação das políticas de expansão do acesso e da permanência na educação superior pressupõe o acompanhamento sistemático dos sujeitos que ingressam no sistema, com o intuito de otimizar a implementação efetiva de tais políticas. Nesse caso, a atuação institucional adquire importância estratégica para o controle da evasão, fazendo-se necessário aos gestores conhecer as expectativas educacionais dos indivíduos que acessam à educação superior, a fim de ampliar o entendimento do fenômeno (TINTO, 1975).

A identificação das causas e a proposição de estratégias de controle da evasão na $\mathrm{EaD}$ também têm sido foco de análises pelos pesquisadores, correspondendo a 19,51\% das dissertações e teses e $12,90 \%$ dos artigos localizados. Tais números, expressivos, levam a crer que se trata de reflexo do processo de expansão do acesso à educação superior nesta modalidade de ensino. Isto é, à medida que o número de matriculados na $\mathrm{EaD}$ aumenta, as preocupações 
com a permanência estudantil também se elevam, em que os pesquisadores se voltam para a busca de respostas que contribuam para o controle da evasão neste modelo de ensino.

A relação entre a evasão e algumas políticas criadas no movimento de expansão também são alvo de discussão, de acordo com o levantamento realizado. A exemplo disso citamse as pesquisas de Cardoso (2008) e Stroisch (2012), que estudam os índices de evasão entre os alunos cotistas em instituições específicas, e os trabalhos de Amaral e Oliveira (2011) e Felicetti e Fossatti (2014), que verificam as taxas de evasão entre os alunos com bolsas do Prouni.

Tanto o estudo de Amaral e Oliveira (2011) quanto o de Felicetti e Fossatti (2014), revelaram que os alunos bolsistas do Prouni apresentam menor chance de se evadirem do curso de ingresso. O trabalho de Cardoso (2008) revela que os alunos cotistas se evadem menos que os não cotistas. Entretanto, Stroisch (2012) observou, a partir dos resultados obtidos com sua pesquisa, que, apesar de ações e programas terem sido implementados, nenhuma ação específica foi realizada para os alunos cotistas, e as ações desenvolvidas não se mostraram eficazes e suficientes para garantir a permanência e o êxito dos alunos, tendo em vista o alto índice de evasão e reprovação nos cursos.

Tais trabalhos contribuem para o processo de avaliação de políticas educacionais, já que apresentam dados significativos que podem ser utilizados na avaliação da implementação das políticas em estudo, sugerindo verificar se seus propósitos, estratégias e execução estão sendo realizados de modo satisfatório, segundo as definições previamente estabelecidas para o processo de avaliação, conforme apresentam Figueiredo e Figueiredo (1986).

O perfil socioeconômico e sua relação com a evasão também foi analisado em alguns trabalhos localizados. Os trabalhos de Braga, Miranda-Pinto e Cardeal (1997) e de Mazzetto e Carneiro (2002) deram enfoque ao perfil socioeconômico dos alunos do curso de Química, sendo o primeiro realizado na Universidade Federal de Minas Gerais (UFMG) e o segundo na Universidade Federal do Ceará (UFC). Constata-se que o curso de Química é um alvo importante para os estudos de evasão estudantil, visto que apresenta, historicamente, índices elevados, até mesmo acima de 70\% em universidades consolidadas do país (BRAGA; MIRANDAPINTO; CARDEAL, 1997).

A ênfase nas questões socioeconômicas, mesmo que de modo secundário, também foi dada em outros trabalhos não incluídos na última categoria citada. Como exemplo tem-se o trabalho de Adachi (2009), incluído na categoria "As causas da evasão em um curso específico ou conjunto de cursos de dada instituição", o qual tratou de estudo de caso na UFMG com o objetivo de analisar a evasão em cinco cursos de graduação no período de 2000 a 2007. Mediante análises quantitativa e qualitativa, os resultados encontrados apontaram maiores índices de evasão nos cursos da UFMG que exigem notas mais baixas para a entrada, cujo perfil discente é de nível socioeconômico e cultural predominantemente baixo, sendo tais cursos de mais baixo prestígio social.

Neste caso, não só o nível socioeconômico pode interferir na permanência do estudante, mas também as questões relacionadas ao capital cultural, que marca a evasão nos diversos sistemas educacionais (BAGGI; LOPES, 2011).

Na categoria "Evasão no sistema de educação superior brasileiro", foram incluídos os trabalhos de Silva Filho et al. (2007) e de Ramos (2013), os quais analisam a evasão do ponto de vista macro, com análises relacionadas ao sistema de educação superior brasileiro. $\mathrm{O}$ artigo 
de Silva Filho et al. apresenta dados de outros países que revelam que a realidade da evasão no Brasil não difere muito da encontrada nas médias internacionais.

Já a tese de Bardagi (2007) e o artigo de Lehman (2014) relacionaram a evasão com desenvolvimento profissional. Bardagi investigou o desenvolvimento da carreira dos estudantes no período da graduação e Lehman, os determinantes que interferem no processo de reescolha profissional.

Estes estudos, relacionados à área da Psicologia, contribuem para as pesquisas relacionadas à educação superior e evidenciam que a temática em discussão não é exclusiva aos pesquisadores vinculados aos programas de pós-graduação em educação. Assim, o estudo de Aguiar (2012) também contribui para tal constatação, uma vez que se trata de pesquisador da área de Bioética, buscando estudar a permanência e evasão do aluno universitário à luz dos referenciais bioéticos da autonomia, equidade e vulnerabilidade.

As tabelas 2 e 3 contêm as áreas de estudo vinculadas aos trabalhos selecionados e reforçam a argumentação em construção.

Tabela 2 - Áreas de estudo vinculadas aos trabalhos analisados (dissertações e teses)

\begin{tabular}{|c|c|c|}
\hline Área de estudo vinculada ao trabalho & № de trabalhos & $\%$ \\
\hline Educação & 13 & $31,70 \%$ \\
\hline Administração & 4 & $9,75 \%$ \\
\hline Psicologia & 4 & $9,75 \%$ \\
\hline Psicologia Clínica e Cultura & 1 & $2,43 \%$ \\
\hline Cultura e Sociedade & 1 & $2,43 \%$ \\
\hline Ensino de Ciências e Matemática & 2 & $4,87 \%$ \\
\hline Ensino de Ciências & 1 & $2,43 \%$ \\
\hline Gestão social, educação e desenvolvimento local & 1 & $2,43 \%$ \\
\hline Serviço Social & 1 & $2,43 \%$ \\
\hline Engenharia de Produção & 1 & $2,43 \%$ \\
\hline Economia & 1 & $2,43 \%$ \\
\hline Odontologia & 1 & $2,43 \%$ \\
\hline Desenvolvimento regional & 1 & $2,43 \%$ \\
\hline Políticas públicas & 1 & $2,43 \%$ \\
\hline Pesquisa operacional e inteligência computacional & 1 & $2,43 \%$ \\
\hline Educação agrícola & 1 & $2,43 \%$ \\
\hline Tecnologia & 1 & $2,43 \%$ \\
\hline Ensino na saúde & 1 & $2,43 \%$ \\
\hline Bioética & 1 & $2,43 \%$ \\
\hline Direito Político e Econômico & 1 & $2,43 \%$ \\
\hline \multirow[t]{2}{*}{ Gestão estratégica de negócios } & 1 & $2,43 \%$ \\
\hline & Total: 41 & Total: $100 \%$ \\
\hline
\end{tabular}

Fonte: Elaboração própria a partir do levantamento de trabalhos realizado 
Tabela 3 - Áreas de estudo da revista/evento em que os artigos foram publicados

\begin{tabular}{lcc}
\hline \multicolumn{1}{c}{ Área de estudo da revista/evento em que o artigo foi publicado } & № de artigos & $\%$ \\
\hline Educação & 16 & $51,61 \%$ \\
\hline Psicologia & 4 & $12,90 \%$ \\
\hline Química & 4 & $12,90 \%$ \\
\hline Economia & 1 & $3,22 \%$ \\
\hline Educação médica & 1 & $3,22 \%$ \\
\hline Enfermagem & 1 & $3,22 \%$ \\
\hline Engenharia agrícola & 1 & $3,22 \%$ \\
\hline Ensino de Física & 1 & $3,22 \%$ \\
\hline Administração & 1 & $3,22 \%$ \\
\hline Sociologia & 1 & $3,22 \%$ \\
\hline
\end{tabular}

Fonte: Elaboração própria a partir do levantamento de trabalhos realizado

É possível verificar que, embora a educação seja a principal área vinculada aos trabalhos analisados, outras áreas também vêm se identificando com os estudos de evasão, gerando novas possibilidades de estudos, com olhares diferenciados ao processo.

Algumas áreas se destacam pela quantidade de trabalhos encontrados, sendo as principais, além da Educação, os ramos da Administração, da Psicologia e da Química, conforme números apresentados nas Tabelas 2 e 3.

Entretanto, o principal destaque a partir desta verificação está na multiplicidade de trabalhos relacionados a áreas bastante distintas. Constata-se que aproximadamente metade do conjunto de artigos em análise (48,39\%) foram publicados em revistas de áreas diversas, não ligadas diretamente à Educação (Tabela 3). Quando se analisa o conjunto de dissertações e teses, os números obtidos são mais expressivos, em que mais da metade $(69,30 \%)$ foram produzidos por pesquisadores de áreas distintas da Educação (Tabela 2).

Esses dados revelam que a evasão é um tema que se destaca no contexto contemporâneo, em que se busca a ampliação do acesso à educação superior, afetando uma multiplicidade de áreas, explicitando a necessidade de mais e maiores estudos, inclusive interdisciplinares e em rede, que permitam análises mais gerais do processo no conjunto das instituições de educação superior brasileiras.

\section{Considerações finais}

O trabalho teve como objetivo produzir um levantamento de estudos sobre evasão de estudantes em cursos de graduação, realizados a partir da década de 1990 no Brasil. Entretanto, para a apresentação dos números obtidos com a pesquisa, considerou-se essencial uma breve exposição do processo de expansão da educação superior nas duas últimas décadas, período em que se verificou a formulação de políticas voltadas, sobretudo, para a elevação do acesso nos cursos de graduação, tanto nas instituições públicas quanto privadas, bem como direcionadas para a permanência estudantil.

Ao buscar os trabalhos relacionados à evasão na educação superior em bancos de dados específicos e sem a utilização de filtro temporal, constatou-se que os estudos selecionados 
para a análise datam de modo unânime da década de 1990 e dos anos 2000, o que coincide com o processo de ampliação do acesso, conforme se visualizou no gráfico 1, ampliando, sobretudo, a partir de 2011, quando passam a ser implementados programas voltados para a permanência estudantil.

Verificou-se que as temáticas pesquisadas se apresentaram diversas, sendo necessária a criação de categorias de análise, com o agrupamento de trabalhos com temáticas próximas em uma mesma categoria, para facilitar a compreensão do fenômeno.

Constatou-se que algumas temáticas são estudadas de modo mais expressivo, sendo que os estudos relacionados às causas e/ou estratégias de controle da evasão em um curso ou instituição específicos respondem por mais da metade dos trabalhos localizados. Esse fato permite observar certo limite nos resultados produzidos por essas pesquisas, uma vez que geram dados com baixo potencial de generalização e em alguns casos divergentes, o que não contribui para a compreensão mais ampla do fenômeno da evasão na educação superior brasileira.

Outra constatação importante está relacionada à área de pesquisa vinculada aos trabalhos analisados. Mais da metade dos estudos estão situados em áreas diferentes da Educação, o que leva a afirmar que a evasão tem sido instigadora aos pesquisadores de ramos bastante distintos da ciência, uma vez que se trata de um fenômeno universal, presente nos mais diversos cursos de graduação.

Nesta direção, acredita-se que a evasão na educação superior, embora com estudos ainda incipientes no Brasil, vem se apresentando como importante temática de pesquisa, em que o estabelecimento de um campo de discussão sólido poderá contribuir para melhor compreensão do processo, tornando-se fator imprescindível para a redução de seus índices, o que, em última instância, coopera para a ampliação do acesso à educação superior no país.

Por fim, o presente trabalho explicitou a necessidade de mais e maiores estudos, inclusive longitudinais e em rede, que permitam análises mais gerais do processo no conjunto das instituições de educação superior brasileiras, ampliando a discussão a partir dos dados das pesquisas aqui levantadas, visando contribuir, de fato, com o campo das políticas educacionais.

\section{Referências}

ABBAD, Gardênia; CARVALHO, Renata Silveira; ZERBINI, Thaís. Evasão em curso via internet: explorando variáveis explicativas. RAE- eletrônica, São Paulo, v. 5, n. 2, Art. 17, p. 01-26, jul./dez. 2006.

ADACHI, Ana Amélia Chaves Teixeira. Evasão e evadidos nos cursos de graduação da Universidade Federal de Minas Gerais. 2009. 214 f. Dissertação (Mestrado em Educação) Programa de Pós-Graduação em Educação, Universidade Federal de Minas Gerais, Belo Horizonte, 2009.

AGUIAR, Gil Emerson Lima. Permanência e evasão do aluno universitário: estudo da experiência do Centro Universitário São Camilo, São Paulo, à luz da Bioética. 2012. 81 f. Dissertação (Mestrado em Bioética) - Programa de Bioética, Centro Universitário São Camilo, São Paulo, 2012. 
ALMEIDA, Leandro et al. Democratização do acesso e do sucesso no ensino superior: uma reflexão a partir das realidades de Portugal e do Brasil. Avaliação, Campinas; Sorocaba, v. 17, n. 3, p. 899-920, nov. 2012.

AMARAL, Daniela Patti; OLIVEIRA, Fátima Bayma. O Prouni e a conclusão do ensino superior: novas trajetórias pessoais e profissionais dos egressos. Ensaio: avaliação e políticas públicas em educação, Rio de Janeiro, v. 19, n. 73, p. 861-890, out./dez. 2011.

BAGGI, Cristiane Aparecida dos Santos; LOPES, Doraci Alves. Evasão e avaliação institucional no ensino superior: uma discussão bibliográfica. Avaliação, Campinas; Sorocaba, v. 16, n. 2, p. 355-374, jul. 2011.

BALL, Stephen J. Diretrizes políticas globais e relações políticas locais em educação. Currículo sem Fronteiras, São Paulo, v. 1, n. 2, p. 99-116, jul./dez. 2001.

BARDAGI, Marúcia Patta. Evasão e comportamento vocacional de universitários: estudo sobre desenvolvimento de carreira na graduação. 2007. 242 f. Tese (Doutorado em Psicologia) - Programa de Pós-Graduação em Psicologia, Universidade Federal do Rio Grande do Sul, Porto Alegre, 2007.

BRAGA, Mauro Mendes; MIRANDA-PINTO, Clotilde Otília Barbosa; CARDEAL, Zenilda de Lourdes. Perfil sócio-econômico dos alunos, repetência e evasão no curso de Química da UFMG. Química Nova, Belo Horizonte, v. 20, n. 4, p. 438-444, 1997.

BRASIL. Diplomação, retenção e evasão nos cursos de graduação em instituições de ensino superior públicas. Relatório da Comissão Especial de Estudos sobre Evasão nas Universidades Públicas Brasileiras. Brasília, DF: ANDIFES/ABRUEM/SESu/MEC, 1997.

BRISSAC, Rafaela de Menezes Souza. Fatores anteriores ao ingresso como preditivos de evasão nos anos iniciais dos cursos superiores de tecnologia. 2009. 149 f. Dissertação (Mestrado em Educação) - Programa de Pós-Graduação, Universidade Estadual de Campinas, Campinas, 2009.

BUENO, José Lino Oliveira. A evasão de alunos. Paidéia, Ribeirão Preto, n. 5, p. 9-16, ago. 1993.

CARDOSO, Claudete Batista. Efeitos da política de cotas na Universidade de Brasília: uma análise do rendimento e da evasão. 2008. 134 f. Dissertação (Mestrado em Educação) Programa de Pós-Graduação em Educação, Universidade de Brasília, Brasília, 2008.

DOURADO, Luiz Fernandes. Reforma do Estado e as políticas para a educação superior no Brasil nos anos 90. Educação \& Sociedade, Campinas, v. 23, n. 80, p. 234-252, set. 2002.

FÁVERO, Osmar; OLIVEIRA, Rosa dos Anjos. Estados da arte e disseminação da pesquisa educacional: nota dos organizadores. Em Aberto, Brasília, v. 25, n. 87, p. 189-191, jan./jun. 2012.

FELICETTI, Vera Lucia; FOSSATTI, Paulo. Alunos ProUni e não ProUni nos cursos de licenciatura: evasão em foco. Educar em Revista, Curitiba, n. 51, p. 265-282, jan./mar. 2014. FELICETTI, Vera Lúcia; MOROSINI, Marília Costa. Equidade e iniquidade no ensino superior: uma reflexão. Ensaio: avaliação e políticas públicas em educação, Rio de Janeiro, v. 17, n. 62, p. 9-24, jan./mar. 2009. 
FERREIRA, Norma Sandra de Almeida. As pesquisas denominadas "Estado da Arte". Educação \& Sociedade, Campinas, SP, v. 23, n. 79, p. 254-272, ago. 2002.

FIGUEIREDO, Marcus Faria; FIGUEIREDO, Argelina Maria Cheibub. Avaliação política e avaliação de políticas: um quadro de referência teórica. Análise \& Conjuntura, Belo Horizonte, v. 1, n. 3, p. 107-127, set./dez. 1986.

FREITAS, Katia Siqueira. Alguns estudos sobre evasão e persistência de estudantes. Eccos-Revista Científica, São Paulo, v. 2, n. 1, p. 247-264, jan./jun. 2009.

GOMES, Alfredo Macedo; MORAES, Karine Numes. Educação superior no Brasil contemporâneo: transição para um sistema de massa. Educação \& Sociedade, Campinas, SP, v. 33, n. 118, p. 171-190, jan./mar. 2012.

KIPNIS, Bernardo. A pesquisa institucional e a educação superior brasileira: um estudo de caso longitudinal da evasão. Linhas Críticas, Brasília, v. 6, n. 1, p. 109-130, jul./dez. 2000.

LEHMAN, Yvette Piha. Estudo sobre universitários em crise: evasão e re-escolha profissional. Estudos de Psicologia, Campinas, v. 31, n. 1, p. 45-53, jan./mar. 2014.

LIMA, Edileusa Esteves. E. A expansão das licenciaturas na UFMG: estratégias de gestão de evasões de alunos face às metas do Reuni. 2012. 144 f. Dissertação (Mestrado em Gestão Social, Educação e Desenvolvimento Local) - Programa de Pós-Graduação em Gestão Social, Educação e Desenvolvimento Local, Centro Universitário UNA, Belo Horizonte, 2012.

MARQUES, Waldemar. Expansão e oligopolização da educação superior no Brasil. Avaliação, Campinas; Sorocaba, v. 18, n. 1, p. 69-83, mar. 2013.

MASSI, Luciana. Relação aluno-instituição: o caso da licenciatura do Instituto de Química da UNESP/Araraquara. 2013. 167 f. Tese (Doutorado em Ensino de Ciências) - Programa de Pós-Graduação Interunidades em Ensino de Ciências, Universidade de São Paulo, São Paulo, 2013.

MAZZETTO, Selma Elaine; CARNEIRO, Cláudia Christina Bravo e Sá. Licenciatura em Química da UFC: perfil sócio-econômico, evasão e desempenho dos alunos. Química Nova, Fortaleza, v. 25, n. 6b, p. 1204-1210, 2002.

MINAYO, Maria Cecília de Souza (Org.). Pesquisa social: teoria, método e criatividade. 32. ed. Petrópolis: Vozes, 2012.

MOROSINI, Marília Costa et al. A evasão na Educação Superior no Brasil: uma análise da produção de conhecimento nos periódicos Qualis entre 2000-2011. In: CONFERENCIA LATINOAMERICANA SOBRE EL ABANDONO EM LA EDUCACIÓN SUPERIOR, 1. 2011, Managua-Nicaragua. Anais... Managua: CLABES, 2011. p. 1-10.

NEY, Otávio Abrantes de Sá. Sistemas de informação acadêmica para o controle da evasão. 2010. 145 f. Dissertação (Mestrado em Engenharia de Produção) - Programa de PósGraduação em Engenharia de Produção, Universidade Federal da Paraíba, João Pessoa, 2010. 
NUNES, R. C. Panorama Geral da Evasão e Retenção no Ensino Superior no Brasil (IFES). In: ENCONTRO NACIONAL DE PRÓ-REITORES DE GRADUAÇÃO, 27., 2013, Recife. Painel... Recife: FORGRAD, 2013. Disponível em: <http://www.forgrad.com.br/apresentacoes/dia1/2013\%20\%20Painel\%20Forgrad\%20Agosto \%20-\%20Evasao.pdf $>$. Acesso em 29 jun. 2014.

OLIVEIRA, Romualdo Portela. Da universalização do ensino fundamental ao desafio da qualidade: uma análise histórica. Educação \& Sociedade, Campinas, v. 28, n. 100, p. 661690, out. 2007

OLIVEIRA, Romualdo Portela. A transformação da educação em mercadoria no Brasil. Educação \& Sociedade, Campinas, v. 30, n.108, p. 739-760, out. 2009.

PARRINO, María Del Carmem. La deserción y la retención de alunos: um viejo conflito que requiere pensar nuevas soluciones. GUAL, Florianópolis, v. 2, n. 1, p. 01-15, 2009.

PEREIRA JUNIOR, Edgar. Compromisso com o graduar-se, com a instituição e com o curso: estrutura fatorial e relação com a evasão. 2012. 98 f. Dissertação (Mestrado em Educação) - Programa de Pós-Graduação em Educação, Universidade Estadual de Campinas, Campinas, 2012.

RAMOS, Lilian das Graças. Dois ensaios sobre aspectos recentes do ensino superior brasileiro. 2013. 108 f. Dissertação (Mestrado em Economia do Desenvolvimento) Programa de Pós-Graduação em Economia, Pontifícia Universidade Católica do Rio Grande do Sul, Porto Alegre, 2013.

RISTOFF, Dilvo. Perfil socioeconômico do estudante de graduação: uma análise de dois ciclos completos do ENADE (2004 a 2009). Cadernos do GEA, Rio de Janeiro, n. 4, 2013.

ROBERTSON, Susan L. O processo de Bolonha da Europa torna-se global: modelo, mercado, mobilidade, força intelectual ou estratégia para construção do Estado?. Revista Brasileira de Educação, Rio de Janeiro, v. 14, n. 42, p. 407-422, set./dez. 2009.

ROMANOWSKI, Joana Paulin; ENS, Romilda Teodora. As pesquisas denominadas do tipo "estado da arte" em educação. Diálogo Educativo, Curitiba, v. 6, n. 19, p. 37-50, set./dez. 2006.

SGUISSARDI, Valdemar. Modelo de expansão da educação superior no Brasil: predomínio privado/mercantil e desafios para a regulação e a formação universitária. Educação \& Sociedade, Campinas, SP, v. 29, n. 105, p. 991-1022, set./dez. 2008.

SILVA, Antônio Simões. Evasão no Ensino Superior. In: ENCONTRO NACIONAL DE PRÓ-REITORES DE GRADUAÇÃO, 25., 2012, Uberlândia. Painel... Uberlândia:

FORGRAD, 2012. Disponível em:

<http://www.forgrad.com.br/documentos/apresentacoes/apresentacoes_xxv_encontro_naciona 1_de_pro_reitores_de_graduacao_antonio.ppt>. Acesso em 16 mar. 2015.

SILVA, Glauco Peres. Análise de evasão o ensino superior: uma proposta de diagnóstico de seus determinantes. Avaliação, Campinas; Sorocaba, v. 18, n. 2, p. 311-333, jul. 2013. 
SILVA, Maria das Graças Martins; VELOSO, Tereza Christina Mertens Aguiar. Acesso nas políticas de educação superior: dimensões e indicadores em questão. Avaliação, Campinas; Sorocaba, v. 18, n. 3, p. 727-747, nov. 2013.

SILVA FILHO, Roberto Leal Lobo et al. A evasão no Ensino Superior brasileiro. Cadernos de Pesquisa, São Paulo, v. 37, n. 132, p. 641-659, set./dez. 2007.

SOUZA, Ângelo Ricardo. A pesquisa em políticas educacionais no Brasil: de que estamos tratando? Práxis Educativa, Ponta Grossa, v. 9, n. 2, p. 355-367, jul./dez. 2014

SOUZA, Juliana Maciel. Trajetória do estudante no curso noturno de Odontologia da Universidade Federal do Rio Grande do Sul: perfil do ingressante, situação acadêmica e motivos de retenção e evasão. 2014. 101 f. Dissertação (Mestrado Profissional em Ensino na Saúde) - Programa de Pós-graduação em Ensino na Saúde, Universidade Federal do Rio Grande do Sul, Porto Alegre, 2014.

STROISCH, Adriane. A permanência e o êxito dos alunos cotistas dos cursos superiores do Campus São José do Instituto Federal de Santa Catarina (2009-2010). 2012. 233 f. Dissertação (Mestrado em Educação) - Programa de Pós-Graduação em Educação, Universidade Estadual de Campinas, Campinas, 2012.

TINTO, Vincent. Dropout from higher education: a theoretical synthesis of recent research. Review of Educational Research, Washington, v. 45, n. 1, p. 89-125, Winter, 1975.

TONTINI, Gérson; WALTER, Silvana Anita. Pode-se identificar a propensão e reduzir a evasão de alunos?: ações estratégicas e resultados táticos para instituições de ensino superior. Avaliação, Campinas; Sorocaba, v. 19, n. 1, p. 89-110, mar. 2014.

TORRES, Rosa María. Educação para todos: a tarefa por fazer. Porto Alegre: ArtMed, 2001 .

TROW, Martin. Reflections on the transition from elite to mass to universal access: forms and phases of higher education in modern societies since WWII. Berkeley: University of California, 2005. Disponível em: <http://repositories.cdlib.org/igs/WP2005-4>. Acesso em 27 abr. 2015.

VELOSO, Tereza Christina Mertens Aguiar. Evasão nos cursos de graduação da Universidade Federal de Mato Grosso, campus universitário de Cuiabá - um processo de exclusão. In:

REUNIÃO ANUAL DA ASSOCIAÇÃO NACIONAL DE PÓS-GRADUAÇÃO E PESQUISA EM EDUCAÇÃO, 24., 2001, Caxambu. Anais... Caxambu: ANPED, 2001. p. 117.

ZAGO, Nadir. Do acesso à permanência no ensino superior: percursos de estudantes universitários de camadas populares. Revista Brasileira de Educação, Campinas, v. 11, n. 32, p. 226-370, maio/ago. 2006. 
José da Silva Santos Junior - Universidade Federal da Grande Dourados Dourados | MS | Brasil. Contato: josejunior_ss@yahoo.com.br

Giselle Cristina Martins Real - Universidade Federal da Grande Dourados Dourados | MS | Brasil. Contato: gcreal@terra.com.br

Artigo recebido em 11 de maio de 2015 e aprovado em 13 de fevereiro de 2017. 